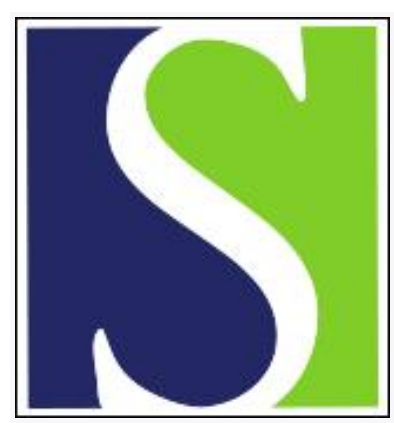

Scand J Work Environ Health 1986;12(4):343-346

https://doi.org/10.5271/sjweh.2132

Issue date: Aug 1986

Applications of hand-arm models in the investigation of the interaction between man and machine.

by Jahn $R$, Hesse $M$

This article in PubMed: www.ncbi.nlm.nih.gov/pubmed/3775320

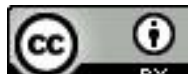




\title{
Applications of hand-arm models in the investigation of the interaction between man and machine
}

\author{
by Reiner Jahn, MScEng, Michael Hesse, MScEng ${ }^{1}$
}

\begin{abstract}
JAHN R, HESSE M. Applications of hand-arm models in the investigation of the interaction between man and machine. Scand $J$ Work Environ Health 12 (1986) 343-346. The mode of vibration of handheld tools cannot be considered without knowledge of the influence of the operator's hand-arm system. Therefore some technical applications of hand-arm models were realized for drill hammers by the University of Dortmund. These applications are a software program to simulate the motion of machine components, a horizontal drilling jig, and a chucking device in a drilling rig.
\end{abstract}

Key terms: automatic test rig, drill hammer acceleration, drilling jig, mechanical impedance.

Comparative measurements of oscillation on vibrating hand-held tools, like drill hammers, chain saws, or grinding machines, in normal use with an operator are possible only with restrictions because of the different feedback of the hand-arm system of individual operators. On the other hand the hand-arm system cannot be ignored during investigations on vibration because the motional behavior of the whole man-machine system is significantly influenced by the hand and arm of the operator. Therefore, for many years, engineers have tried to simulate the dynamic qualities of a representative human hand-arm system with mechanical models.

This report is essentially restricted to applications of technical hand-arm models for investigations on electric drill hammers and impact drilling machines. Their use has spread during the last two decades because of their easy handling and efficiency.

\section{Hand-arm models}

Figure 1 shows a selection of experimentally determined impedance characteristics of the human handarm system. They are valid for loading the extended or flexed arm in the longitudinal axis of the forearm as measured by different scientists.

As shown in the figure, most of the impedance characteristics do not cover all of the frequency range from 6 to $1000 \mathrm{~Hz}$ that is of interest in this case, and they partially deviate one from another. The different test parameters, like grip force, feed force, arm bearing, etc, and the dissimilar experimental techniques may be primarily responsible for this deviation. These parameters had not, however, been described precisely at all. The mechanical hand-arm models developed by

\footnotetext{
1 University of Dortmund, Metal Cutting Department, PO Box 500500, D-4600 Dortmund 50, Federal Republic of Germany.
}

Reprint requests to: $\mathrm{Mr} \mathrm{M}$ Hesse, Universität Dortmund, Institut für spanende Fertigung, Postfach 500500, D-4600 Dortmund 50, Federal Republic of Germany. scientists working on impedance measurements $(1,4$, $5,6,7,8,9,10,12$ ) (their different structures are shown for one direction in figure 1) vary in complexity and are valid, of course, only for the hand-arm characteristics, grip and feed forces, and arm positions adopted during the impedance measurements.

Some of the models are suitable only for theoretical investigations and technical realization is impossible, either because of the complexity of the structure of the models or, in part, because of the extremely low masses or rigidity of the spring elements. Another reason for the technical unfittedness of some models is the different values stated for the coupling masses in different directions.

\section{Mathematical model of a drill hammer}

The first of the three applications presented in this report refers to the numerical simulation of the motion of the main parts of electropneumatic drill hammers. During a scientific investigation by the University of Dortmund (11) a computer program was developed to obtain knowledge about the essential reasons for the vibration of drill hammers and to evaluate the vibration effects of constructive modifications of the batting unit.

Figure 2 shows a mechanical model of a drilling machine with a batting unit based on a pneumatic cushioning. The dynamic specifications of the hand-arm system are simulated by a mechanical model elaborated by Meltzer et al and published in 1980 (6). The model is valid in the frequency range from 10 to $500 \mathrm{~Hz}$, and it possesses three degrees of freedom. The program includes the variation of parameters which are essential for the construction of percussive boring machines, such as the length of the pneumatic spring, batting piston diameter, crank arm radius, masses of the different pistons, the case, the blow rate, the feed force, data on the damping ring, etc. Moreover it is possible to consider different grip cushionings.

The mechanical dimensions of a real drill hammer 

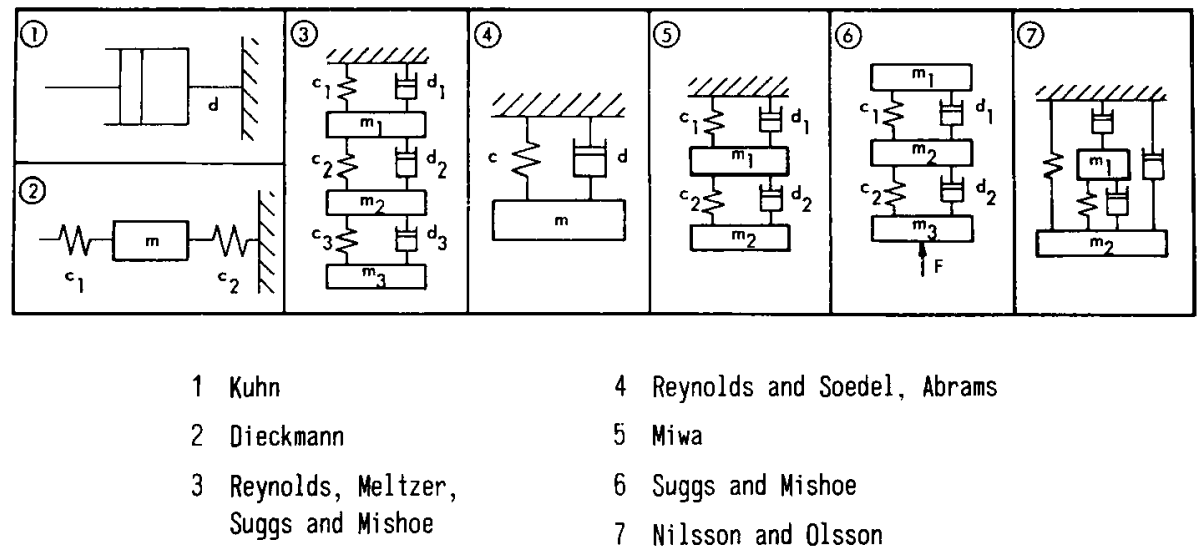

4 Reynolds and Soedel, Abrams

5 Miwa

6 Suggs and Mishoe

7 Nilsson and 0lsson

Figure 1. Mechanical hand-arm models (one direction) $(3,5,7,8,9,12)$.

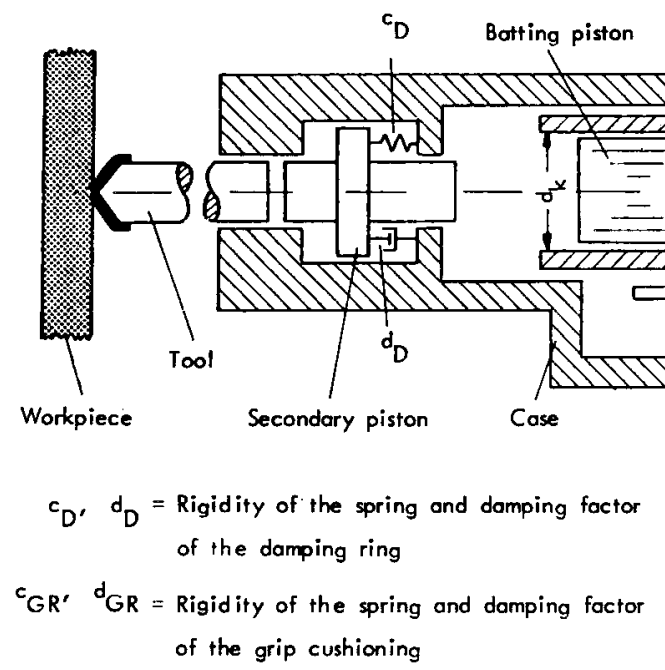

Figure 2. Mechanical model of a drill hammer.

calculated with the help of the program are shown in figure 3 . One can see that the case acceleration is marked by distinctive acceleration peaks superimposed on a base curve similar to a sine wave. This curve results from a combination of the maximum compression of the pneumatic spring (the peaks of which are indicated by LF in figure 3) and the impact of the secondary piston on the damper element which leads to narrow but high peaks ( $\mathrm{D}$ in the figure). Moreover, the case of the drill hammer hits the collar of the secondary piston during its motion towards the tool. This is called the B impact, and it causes another peak in the case acceleration curve.

\section{Horizontal drilling jig}

The second application is the hardware construct of a mechanical hand-arm model for vibration measurements on drill hammers. Measurements on hand-held tools generally lead to large data errors and data variances, which are mainly caused by the influence of the operator. In order to eliminate these influences in comparative measurements of drill hammer vibration, a drilling jig with an artificial hand-arm system, shown in figure 4, was built. With this jig the drill hammer is pressed against the workpiece during the drilling process. The hand-arm system of this device has three degrees of freedom and is also based on the hand-arm model developed by Meltzer et al (6).

The mechanical hand-arm model can be directly fixed to the grip of the drill hammer. The drill hammer can be moved in the longitudinal direction and is suspended by a low-friction guide. A brace for the drilling torque is also available, so that the torque does not affect the hand-arm model. The mass $\mathrm{m}$, which is relatively large, causes a dynamic decoupling between the feed force $G$ and the mechanic hand-arm model.

One of the important factors in the development of the hand-arm model is the construction of the dashpots. Each one of these dashpots consists of a piston running in a collar. The ring gap between the piston and cylinder must be manufactured precisely, and it must be filled with a suitable oil or grease. The com- 


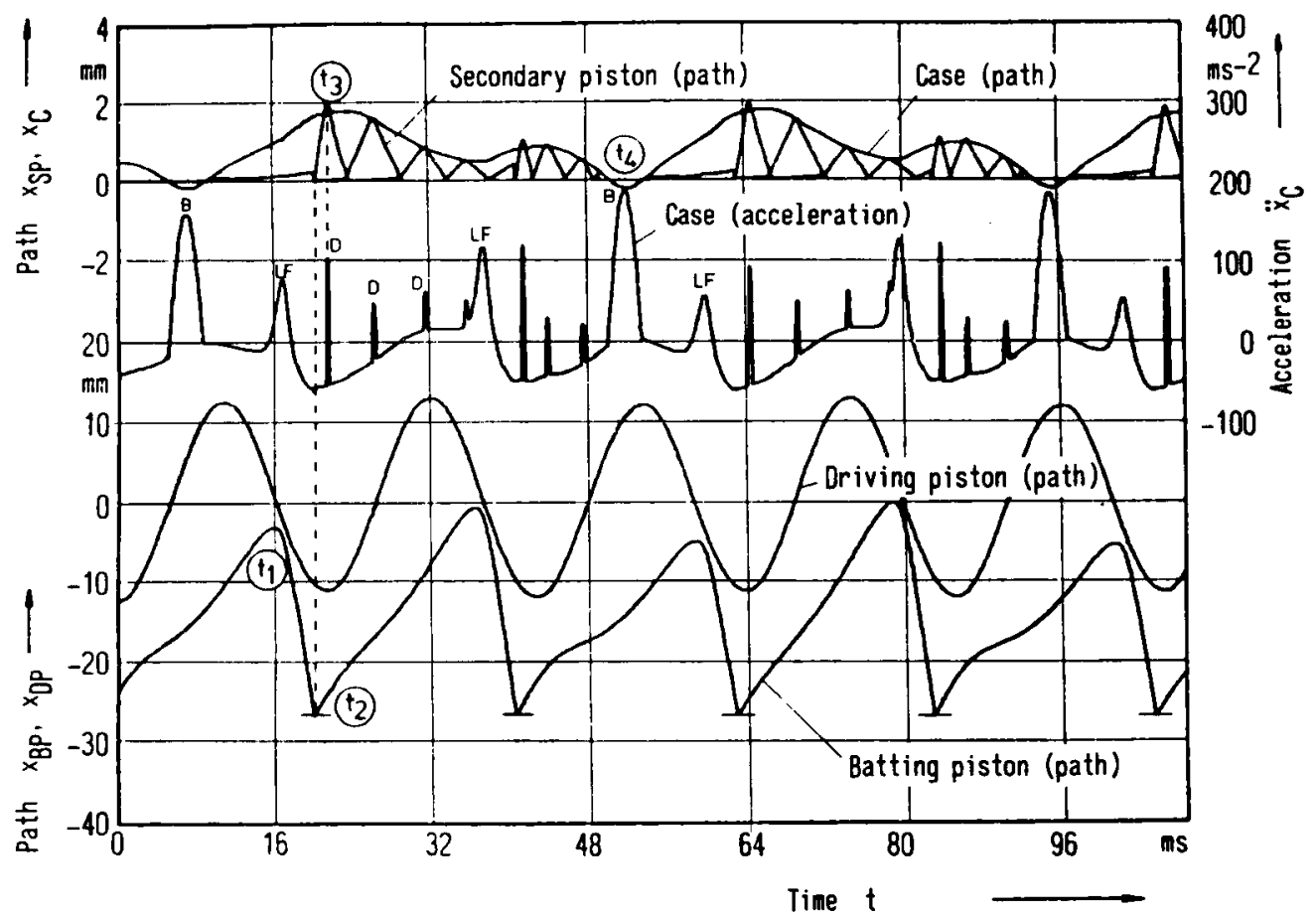

Figure 3. Displacement and acceleration of several drill hammer elements.

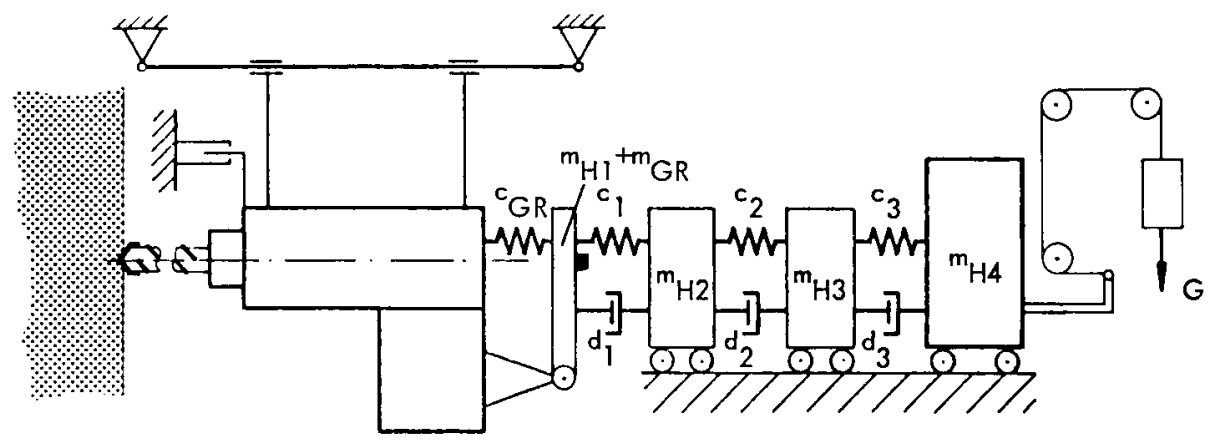

Figure 4. Horizontal drilling jig.

position of the oil, especially its dynamic viscosity, is an important factor which had to be determined by experiment.

For example, using the horizontal test rig with Meltzer's hand-arm model gives a variance coefficient that is about $9 \%$ lower ( $3 \%$ against $12 \%$ ) in acceleration measurements on the Bosch 11206 drill hammer than the values obtained in the usual hand-held operation (data from five persons, seven measurements each).

\section{Automatic drilling rig}

The third application is an automatic hammer drilling rig for the execution of endurance tests with drill hammers and drilling tools. For such investigations a large number of tests are necessary. Until now these tests have been performed by an operator, who will be exposed to damaging vibration, noise, and dust. Therefore the University of Dortmund has developed a microprocessor-controlled drilling test rig (2). This test rig has been installed in several companies. It is able to drill any arrangement of drill holes without the requirement of an operator to monitor its operation. The microprocessor system is able to recognize different kinds of failures (eg, fracture of the drilling tool, clamping of the drilling tool, overheating of the drill hammer) and to react to these failures in an adequate manner. The drill hammer is to be chucked in the universal flexible coupling which is shown in figure 5 . The vertical oscillatory motions, ie, those in the drilling direction, are mainly influenced by coil springs. Oscillatory motions in the horizontal direction are mainly influenced by rubber elements. In order to get good agreement between the dynamic behavior of the model and the human hand-arm system the movable masses of the coupling should be as small as possible. 


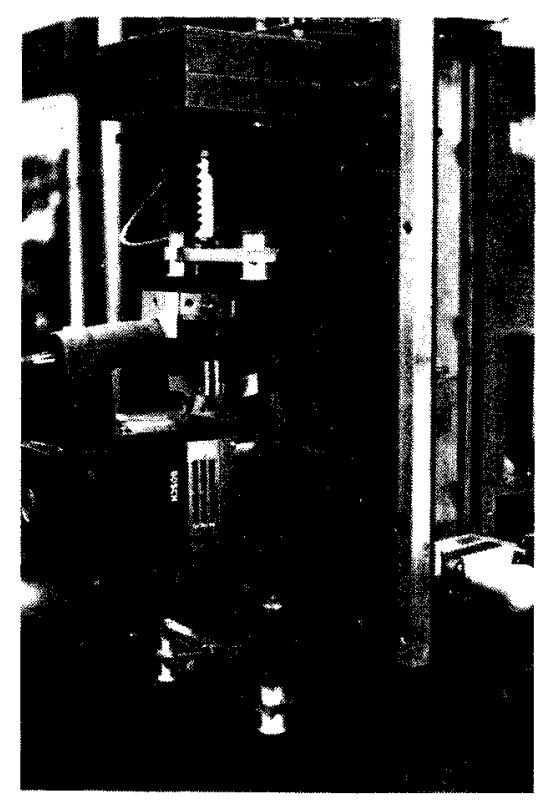

Load weight

Coil spring

Rubber spring

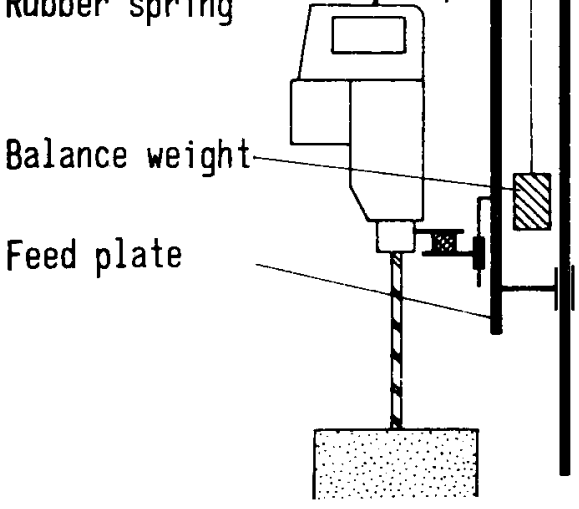

Figure 5. Flexible drill hammer coupling.
For the construction of the coupling for the drill hammer none of the existing hand-arm systems could be used. Either it was impossible because of one of the aforementioned reasons (degrees of freedom, low masses, low spring rigidities, different coupling masses). or the applied test parameters (feed and grip forces, arm bearings) differed too much from those parameters which were suitable for the planned task. Another reason may have been the large space needed for the technical realization, for example, with Meltzer's model.

In order to achieve conformity between the impedance characteristic of the flexible coupling and the human hand-arm system, a comparison was made with the use of vibration and power data obtained from the machines while they were being operated by hand. A systematic variation of the springs and rubber elements was made until there was agreement between the frequency-weighted effective acceleration measured on the handle according to DIN 45675 (3), the feed rate and the drill power while in an automatic service state and the equivalent data while in a hand-held service state.

The automatic test rig is used by several companies in order to make endurance tests of their drilling tools. On the basis of their experience, it has become possible to perform tests in a shorter time than before. The test results (endurance) are similar to those obtained for a hand-held service state. Therefore the rig makes it possible to carry out a greater number of endurance tests in the same time with less personnel.

\section{References}

1. Abrams CF. Modeling the vibrational characteristics of the human hand by the driving point mechanical impedance method. North Carolina State University, Raleigh, NC 1971. (Doctoral dissertation).
2. Cronjäger L, Jahn R, Riederer H. Entwicklung eines Versuchsstandes zur reproduzierbaren Messung der Vibration schlagender handgeführter Maschinen. Forschungsbericht des Landes NRW Nr 3185. Westdeutscher Verlag, Opladen 1984.

3. Deutsches Institut für Normung e.V. (DIN). Assessment of the effect of mechanical vibrations on human beings: Measurement and evaluation of vibration transmitted to the hand-arm system. Beuth Verlag, Berlin 1984. (Draft proposal DIN 45675, part 1).

4. Dieckmann D. Ein mechanisches Modell für das schwingungserregte Hand-Arm-System des Menschen. Int Z Angew Physiol einschl Arbeitsphysiol 17 (1958) $125-132$.

5. Kuhn F. Über die mechanische Impedanz des Menschen bei der Arbeit mit dem Preßlufthammer. Arbeitsphysiologie 15 (1953) 79-84.

6. Meltzer G, Melzig-Thiel R, Schatte M. Ein mathematisches Schwingungsmodell für das menschliche HandArm-System. Maschinenbautechnik 29 (1980): 2, 54-58.

7. Miwa T. Studies on hand protectors for portable vibrating tools. Ind Health 2 (1964) 95-105.

8. Nilsson A, Olsson E. Test rig for vibration control on chain saws, development and design of a test rig with two artifical hands. University Lulea 1978. (Technical report 1978: $49 \mathrm{~T}$ ).

9. Reynolds DD, Keith RH, Angevine EN. Hand-arm vibration: Part 1. Analytical model of the vibration response characteristics of the hand. Part 2. Vibration transmission characteristics of the hand and arm. Part 3. Subjective response characteristics of individuals to hand-induced vibration. J Sound Vib 51 (1977): 2, $237-282$.

10. Reynolds DD, Soedel W. Dynamic response of the handarm-system to a sinusoidal input. J Sound Vib 21 (1972): $2,339-353$.

11. Riederer H, Jahn R. Numerische Simulation der Bohrhammerbewegungen beim schlagenden Bohren. Ind Anz 104 (1982): 12, 29-30.

12. Suggs CW, Mishoe JW. Hand-arm vibration: Implications drawn from lumped parameter models. In: Wasserman DE, Taylor W, Curry MG, ed. Proceedings of the international occupational hand-arm vibration conference. National Institute for Occupational Safety and Health, Cincinnati, OH 1977, pp 136-141. (DHEW publication no $77-170$ ). 